\title{
Multifactorial control of autoimmune insulin- dependent diabetes in NOD mice: Lessons for IBD
}

\author{
EDWARD H LEITER PhD
}

EH LEITER. Multifactorial control of autoimmune insulin-dependent diabetes in NOD mice: Lessons for IBD. Can J Gastroenterol 1995;9(3):153-159. Development of autoimmune insulin-dependent diabetes mellitus in nonobese diabetic (NOD) mice is an example of a complex multifactorial disease with strong genetic and environmental components. As such, this model may provide insight not only into mouse models of inflammatory bowel disease, but also may provide insight into how the environment may interact with the genome to initiate pathogenesis in humans. NOD mice are characterized by accumulation of unusually high percentages of T lymphocytes in lymphoid organs. Pancreatic beta cell destruction in NOD mice is T lymphocyte-mediated. Complex interactions between the inherently diabetogenic major histocompatibility complex (MHC) haplotype of this strain and non-MHC-associated insulin-dependent diabetes susceptibility genes (Idd) are required for cytopathic activation of the leukocytic infiltrates in the pancreas (insulitis). Penetrance of the diabetogenic Idd genes is strongly influenced by both dietary and microbiological factors in the environment. Genetic susceptibility is transmitted by hemopoietic stem cells, and specific defects in $\mathrm{T}$ immunoregulation have been traced to defects in the development and function of marrow-derived antigen presenting cells. The spontaneous development of diabetes in NOD mice is different from experimentally induced forms of diabetes in mice in several important respects. In addition to the pathognomic development of pancreatic insulitis, the generalized loss of immunoregulatory control of autoreactive $\mathrm{T}$ lymphocytes in NOD mice is reflected by development of leukocytic infiltrates into a plethora of organ systems including the submandibular salivary glands, thyroid glands, kidneys and, occasionally, the colon. (Pour résumé, voir page 154)

Key Words: Autoimmunity, Diabetes, Genetics, Nonobese diabetic (NOD) mice

The Jackson Laboratory, Bar Harbor, Maine, USA

Correspondence and reprints: Dr EH Leiter, Senior Staff Scientist, The Jackson Laboratory, Bar Harbor, ME 04609, USA. Telephone (207) 288-3371, Fax (207) 288-5079

This paper was presented at the Basic Research and Clinical Implications in IBD meeting, April 6 to 9, 1994, held in Victoria, British Columbia. This paper has also been published in Sutherland LR, et al, eds. Inflammatory Bowel Disease: Basic Research, Clinical Implications and Trends in Therapy. Boston, Dordrecht and London: Kluwer Academic Publishers, 1994
$\mathrm{T}$ HE MOUSE HAS BEEN A FAVOURED organism for development of models of human genetic diseases. The mouse genome is over $85 \%$ homologous with the human genome. Compared with other nonhuman mammalian genomes, the mouse genome has been extensively characterized and is readily amenable to manipulation by transgenic or gene targeting technologies. Inbred mice have been extensively employed to analyze the complex interplay between genes and environment in the development and control of immune responsiveness to antigens. A multiplicity of genes with known effects on immune responsiveness has been mapped. The use of gene targeting to elicit null mutations in specific interleukin (IL) genes (eg, I12, I14, 1110, $T g f b 1)$ or $\mathrm{T}$ cell receptor genes renders mice susceptible to intestinal inflammation. Indeed, in certain of these gene 'knockout' mice, mucosal inflammation is often the most profound lesion observed, perhaps because mucosal epithelium and attendant gut-associated lymphoreticular tissue, unlike internal tissues, are under constant antigenic bombardment (1). Cytokine imbalances elicited by targeting specific interleukin genes may lead to loss of $\mathrm{T}$ lymphocyte-mediated sup- 


\section{Maîtrise plurifactorielle du diabète insulino-dépendant auto-immun chez la souris : des leçons à tirer pour les MII}

RÉSUMÉ : L'installation d'un diabète sucré insulino-dépendant auto-immun chez des souris diabétiques non obèses (DNO) est un exemple de maladie plurifactorielle complexe dotée de fortes composantes génétiques et environnementales. À ce titre, un tel modèle peut éclairer, non seulement les modèles de maladies inflammatoires de l'intestin chez la souris, mais expliquer également en partie comment l'environnement peut interagir avec le génome pour précipiter la pathogenèse chez l'humain. Les souris DNO sont caractérisées par une accumulation de pourcentages anormalement élevés de lymphocytes T dans les organes lymphoïdes. La destruction des cellules pancréatiques bêta chez les souris DNO est liée aux lymphocytes T. Les interactions compliquées entre l'haplotype du complexe majeur d'histocompatibilité (CMH) essentiellement diabétogène de cette souche et des gènes de susceptibilité au diabète insulino-indépendant (did) non associés aux CMH sont nécessaires pour l'activation cytopathique des infiltrats leucocytaires dans le pancréas (insulite). La pénétrance des gènes did diabétogènes subit une forte influence des facteurs alimentaires et microbiologiques de l'environnement. La susceptibilité génétique est transmise par les cellules souches hématopoiétiques et des défauts spécifiques de l'immunorégulation $\mathrm{T}$ ont été associés à des anomalies du développement et de la fonction des cellules médullaires de présentation antigénique. L'installation spontanée de diabète chez des souris DNO diffère des formes de diabète induites expérimentalement chez des souris et ce, à divers chapitres. En plus du développement pathognomique de l'insulite pancréatique, la perte généralisée de l'immunorégulation des lymphocytes $T$ autoréactifs chez la souris DNO se reflète par l'installation d'infiltrats leucocytaires dans de nombreux systèmes, y compris les glandes salivaires sous-mandibulaires, les glandes thyroïdiennes, les reins et, à l'occasion, le côlon.

pression of $\mathrm{B}$ lymphocyte responses to mucosal antigens (1). Differential sensitivity of certain inbred strains to colonic inflammation induced by the macrophage activating agent, dextran sulphate (2), affords a promising avenue for identifying major genes associated with acute inflammatory responsiveness leading to ulceration of the lower bowel. In addition, identification of a spontaneous, juvenile onset colitis in $\mathrm{C} 3 \mathrm{H} / \mathrm{HeJBir}$ mice (3) affords yet another promising tool for dissecting the complex relationship between genes and environment that must underlie most instances of inflammatory bowel disease (IBD) in humans.

Genetic factors presumably comprise a major component of susceptibility to IBD in humans (4). For example, first-degree relatives of Ashkenazi Jews are at higher risk for IBD development than are first-degree relatives of nonJewish IBD patients in the same neighbourhoods (5). Human leukocyte antigen (HLA)-B27 is a human major histocompatibility complex (MHC) class I allele associated with susceptibility to inflammation of joints, as well as of the gastrointestinal and urogenital tracts. Lewis rats transgenically expressing both HLA-B27 and human beta-2-microglobulin (B2M) genes develop a variety of multi-organ inflammatory disorders, including IBD (6). IBD is a genetically heterogeneous group of disorders, since susceptibility to ulcerative colitis (UC) and Crohn's disease (CD) is associated with different MHC class II alleles (DR2 versus DR1/DQW5, respectively) (7).

Insulin-dependent diabetes mellitus (IDDM) is a prototypic example of another genetically heterogenous, multifactorial disease that geneticists have been grappling with for many years. Until it was recognized that IDDM had an entirely different etiopathogenic basis from the more common forms of human diabetes, collectively referred to as noninsulin dependent diabetes mellitus (NIDDM), little progress was made. Although advances in knowledge have made IDDM less of the 'geneticist's nightmare' that it formerly was, the polygenetic interactions underlying IDDM in humans is still only poorly understood. A common observation regarding IDDM inheritance in nonconsanguinous human pedigrees was that the disease did not appear in every generation. This underscores the multifactorial nature of this genetically complex disease. IDDM in affected probands likely reflects heterogeneous admixtures of polygenes reassorting throughout the pedigree. The penetrance of susceptibility genes within these changing polygenic combinations likely is responsive to different thresholds of intragenic as well as environmental influences. The importance of various MHC class II (HLA-DR and DO) alleles as primary determinants of susceptibility in humans (8-10) is clearly established. What remains unclear is whether a finite set of non-MHC susceptibility genes is being segregated, or whether different combinations of polygenes interact deleteriously with IDDM-predisposing HLA alleles in different environments.

Genetic analysis of IDDM susceptibility in nonobese diabetic (NOD) mice provides insight into this question. Currently the products of over 60 generations of brother $\mathrm{X}$ sister matings, NOD mice inherit the same sex-specific set of susceptibility genes through the germ line. The genetics and immunology of diabetes in NOD mice has been reviewed recently (11-14). The present report attempts to distil some of the insights gained from genetic and immunologic analysis of NOD mice to project how mouse models of spontaneous IBD may compare with experimentally induced models. The complexity of the polygenetic control of IDDM in NOD mice is also discussed in the context of the search for IBD susceptibility genes in humans.

\section{MHC CONTROL OF DIABETOGENESIS IN NOD MICE}

In mice, autoimmune diseases associated with a number of single gene mutations can be transferred into genetically normal mice following lethal irradiation and reconstitution with bone marrow from mutant mice (15). 
In both the NOD mouse and the BioBreeding (BB) rat (another model of spontaneous IDDM), IDDM can also be transmitted via hematopoietic stem cells (13). Two recent case reports $(16,17)$ indicate that IDDM etiopathogenesis in humans also originates as specific defects expressed at the level of bone marrow stem cells. In both case studies, autoimmune diabetes or its preclinical symptoms appear to have been inadvertently transferred by bone marrow transplantation from HLA-matched donors who subsequently developed autoimmune IDDM. Since marrow from the HLA-B27/B2M transgenic Lewis rat elicits IBD in irradiated hosts, this model clearly shares etiopathogenic features with autoimmune IDDM in NOD mice and BB rats. As mentioned above, HLA-DR class II genes have been identified with risk for development of UC and $\mathrm{CD}$, whereas HLA-B27 is a class I gene. Presumably, a combination of genes including both MHC class I and class II alleles, and perhaps other intra-MHC loci, is necessary to confer high IBD risk. MHC control of diabetogenesis in the NOD mouse has provided insight into this issue.

The unique MHC haplotype $\left(\mathrm{H} 2^{g 7}\right)$ of NOD mice represents the major component of IDDM susceptibility (18). It should be noted that the uniqueness of this diabetogenic MHC distinguishes it from the relatively common MHC haplotype of IDDM-prone BB rats $\left(R T 1^{u}\right)$ and the relatively common HLA haplotypes associated with high IDDM risk in Caucasians. As reviewed by Kikutani and Makino (11), DNA sequence analysis shows that the NOD $A \beta$ gene (the homologue to human $D Q B$ ) has a 'diabetogenic' substitution of histidine and serine in place of proline and aspartic acid at residues $56-57$ (9). This $A \beta^{g 7}$ is quite rare in mice, and its diabetogenic potency has been verified by sitespecific mutagenesis to restore either the proline or the aspartic acid codons. transgenic insertion of either modified $A \beta$ construct into NOD zygotes prevented IDDM. as confirmed by transgenic insertion of a wild-type allele, another diabetogenic component of $\mathrm{H}_{2}{ }^{\mathrm{g} 7}$ is a mutation in the $E \alpha$ gene (homologue to human $D R \alpha$ ) prevent- ing expression of I-E molecules on the cell surface of antigen presenting cells (APC). In addition to these two MHC class II alleles, diabetogenesis requires additional genes within the $\mathrm{H} 2^{\mathrm{g} 7}$. CTS is an NOD-related inbred strain sharing the same MHC class II and class III alleles as NOD, but differing at MHC class I loci. This MHC haplotype $\left(\mathrm{H}_{2}{ }^{\mathrm{ct}}\right)$ is less diabetogenic than $\mathrm{H}_{2}{ }^{\mathrm{g}}$ when transferred onto the NOD inbred strain background. Thus, while the MHC class I alleles expressed by the $\mathrm{H}^{\mathrm{g} 7}$ haplotype are not rare, they are diabetogenic when paired with the specific combination of MHC class II and class III alleles contained within the haplotype.

A locus encoding heat shock protein 70 (Hsp70) within the class III region, as well as a locus in the region between $\mathrm{H} 2 \mathrm{~K}$ and $\mathrm{A} \beta$ encoding a transporter associated with antigen processing (Tap1) are among the rare alleles associated with the $\mathrm{H}^{\mathrm{g} 7}$ haplotype. Although a null mutation preventing Tap1 gene expression in NOD APC (leading to subsequent low levels of cell surface class I available to present to [and to tolerate] self-antigens) has been proposed as the basis for $\mathrm{H} 2^{\mathrm{g} 7}$-induced susceptibility (19), this proposition has not been supported (20-22). Knockout of the mouse Tap1 gene by homologous recombination produces mice lacking CD8 $+\mathrm{T}$ cells (23). Deficiency of CD8+ T cells is not a phenotype descriptive of NOD mice. A strain-specific feature of NOD mice is $T$ cell accumulation in the periphery, represented by increases in the percentages of both CD4+ and CD8+ T cells in lymphoid organs, with a coincident decrease in the percentage of $\mathrm{B}$ lymphocytes. Diabetogenesis in NOD mice is $\mathrm{T}$ cell-mediated. NOD/Lt mice homozygous for the severe combined immunodeficiency (scid) mutation cannot generate functional $\mathrm{T}$ or $\mathrm{B}$ lymphocytes. These mutant mice develop neither insulitis nor IDDM. Splenic T cells from wild-type NOD/Lt mice transfer insulitis and diabetes into unirradiated NOD-scid/scid recipients. Both MHC class II restricted CD4 $+\mathrm{T}$ cells and MHC class I restricted CD8 $+\mathrm{T}$ cells are required to initiate beta cell patho- genesis in this adoptive transfer model (24). NOD mice homozygous for a B2m gene inactivated by homologous recombination do not express MHC class I molecules on cell surfaces and, as expected, the thymus fails to select positively a peripheral CD8+ $\mathrm{T}$ cell repertoire. Not surprisingly, these $\mathrm{CD} 8+\mathrm{T}$ cell-deficient mice are incapable of triggering the initial lesions required for development of destructive insulitis and IDDM development $(25,26)$.

Transfer of the NOD $\mathrm{H} 2^{g 7}$ haplotype onto the NON/Lt inbred strain background only rarely elicits IDDM, despite that NON mice are closely related to NOD mice and are the product of selection for impaired glucose tolerance (11). This clearly illustrates that the MHC component of diabetogenesis requires the presence of (and very likely interaction with) non-MHC susceptibility genes, referred to as Idd (insulin-dependent diabetes) loci. Non-MHC genes contribute to numerous defects in APC differentiation and function that reduce the stimulatory capacity of these cells (27). Given the importance of normal APC function in development and maintenance of tolerance to autoantigens, the genetically controlled APC dysfunctions in NOD mice undoubtedly contribute to this strain's inability to prevent the generation and activation of autoreactive $\mathrm{T}$ cells. The NOD's immune system does not mount an isolated, organ-specific autoimmune attack only on the pancreatic beta cells. Instead, a variety of tissues and organs are affected by immunoregulatory defects in NOD mice. Indeed, when IDDM is prevented in NOD mice by maintaining the mice on a semipurified diet instead of diabetogenic natural ingredient diets, a broad array of tissue infiltrates is observed. Affected organs and tissues include submandibular glands, thyroid, kidney, lacrimal and Harderian glands, central nervous system and the large bowel.

The chromosomal locations of certain of the non-MHC Idd genes and the influence of environment on the penetrance of these genes have been reviewed recently (12). An important 
insight gained from the genetic analysis of IDDM susceptibility in NOD mice is that the NOD genome contains but one subset of a much larger set of potential Idd genes predisposing to autoimmune disease. To illustrate, when NOD mice are outcrossed to inbred strains such as C57BL/6J (B6) or C57BL/10J (B10), F1 hybrids are uniformly IDDM-free. The conclusion is that the complex polygenic interactions between the specific set of NOD-derived MHC and non-MHC genes required for diabetogenesis have been disrupted. These F1 hybrids must be backcrossed to NOD mice to establish the minimum number of Idd genes required to mediate diabetogenesis and their chromosomal locations. When such a backcross is performed and the genotypes of the diabetic probands determined, new diabetogenic combinations of polygenes distinct from the diabetogenic subset in the NOD genome are uncovered (28). That is, the genome of the IDDM-resistant partner strain (B6 or B10) contains certain alleles that are even more diabetogenic than the NOD-derived alleles. Hypothetical examples of how susceptibility factors could derive from the 'resistant' strains are easy to provide. For example, natural killer (NK) activity is defective in NOD, but not in B6 or B10, mice. If more functional NK cells in an insulitic lesion provide an additional cytopathic component, and if B6/B10 mice transmit an allele allowing normal NK function, then the resistant strain would be perceived as contributing to the penetrance of the diabetic phenotype in hybrid mice. Thus, the genome of the NOD mouse represents but one subset of a larger spectrum of potentially pathogenic gene combinations.

When the NOD-specific diabetogenic interactions are disrupted by outcross and then reassorted into diabetogenic combinations through intercross or backcross progeny, the same fixed set of IDDM susceptibility modifiers defining the NOD genome need not be fully reconstituted to elicit IDDM. In human terms, this means that the genetic mechanisms underlying diabetogenesis in NOD mice might be applicable to IDDM in some human pedigrees but not in others. Identification of the physical nature of the non-MHC Idd susceptibility genes in NOD mice will allow medical geneticists to search for the human homologues and to assess their contribution to IDDM risk at both the population and family level. However, the evidence that IDDM is genetically heterogeneous in both mice and humans renders it unlikely that the same collection of Idd genes contributing to IDDM susceptibility in NOD mice would be faithfully mirrored in the randomly mating human population. The present author predicts that a similar level of genetic heterogeneity will underlie susceptibility to IBD. Specifically, even if the genetic basis for UC or CD susceptibility were completely understood in a given animal model, the profile of the human homologues of these loci would fit only a subset of the individuals affected with the respective disease.

\section{COMPARISON OF INDUCED VERSUS SPONTANEOUS MODELS OF IDDM}

A number of models exist for experimentally inducing IBD in rodents by exposure to inflammatory or microbial agents. Since IDDM can be elicited in male mice by administration of multiple low doses of the fungal antibiotic streptozotocin (SZ), it is instructive to compare etiopathogenesis with the spontaneous IDDM developing in NOD mice. In males of certain inbred strains, IDDM induction by multidose SZ is associated with insulitis development. The issue has been whether the insulitis was a response to inflammation induced by the direct beta cell cytotoxic effects of SZ, or whether it represented an autoimmune, $\mathrm{T}$ cell-mediated destruction as observed in NOD mice (29). NOD-scid mice provide a useful means for testing the ability of leukocytes to transfer IDDM adoptively. Young NOD males treated with multidose SZ rapidly become hyperglycemic several months before spontaneous IDDM customarily develops. Yet splenic leukocytes from these SZ-diabetic males cannot adoptively transfer disease into NOD-scid mice. In contrast, splenic leukocytes from spontaneously diabetic NOD male donors rapidly transfer insulitis and diabetes into NOD-scid mice (30). Thus, the immune system exerts a primary pathogenic role in the spontaneous model but not in the chemically induced model. In IBD induced in mice by dextran sulphate feeding, leukocytic involvement also appears to be a secondary response to inflammatory damage rather than its cause because the colonic lesions can also be elicited in scid mice (personal communication).

It is of further interest to compare the $\mathrm{T}$ cell-mediated diabetes developing in NOD mice with other induced inflammatory diseases, such as murine experimental allergic encephalomyelitis (EAE). Inbred strain sensitivity to EAE following injection of fragments of myelin basic protein in complete Freund's adjuvant (CFA) is MHC-dependent, and the $\mathrm{T}$ cell repertoire is oligoclonal (31). In marked contrast, diverse, polyclonal $\mathrm{T}$ cell receptor $\mathrm{V} \beta$ gene use by islet-infiltrating $T$ cells has been demonstrated in the early stages of insulitis in NOD mice $(32,33)$. One other interesting distinction between the EAE model and spontaneous IDDM in mice is that, whereas CFA is essential to prime $T$ cells to the myelin basic protein fragments in the EAE model, administration of CFA to prediabetic NOD mice completely suppresses IDDM development (34). Based on differences in cytokine MRNA profiles of isletinfiltrating $T$ cells in CFA-treated versus - untreated NOD mice, it has been suggested that a predominance of $\mathrm{T}$ helper 1 (Th1) subset of CD4+ T cells expressing IL-2 and interferon (IFN)-gamma are particularly diagnostic of a destructive $T$ cell infiltration of pancreatic islets, whereas a shift in infiltrate composition to the Th2 phenotype (producing IL-4 and IL-10 MRNA) reflects a less pathogenic population (35). However, recent studies in the author's laboratory indicate that this view may be overly simplistic. The author and colleagues analyzed, by polymerase chain reaction, the cytokine profiles in islet-infiltrating macrophages and $\mathrm{T}$ cells under conditions in which diabetogenesis was either retarded or accelerated. Reductions in macrophage and CD8-associated MRNA 
levels correlated with protective treatment (intrathymic islet cells presumably eliciting tolerance). Although both IL- 2 and IFN- $\gamma$ have been used to classify the Th1 phenotype, the author's data indicated protection was associated with upregulated IL-2 while IFN- $\gamma$ MRNA decreased. These results indicate that changes in the overall profiles of monokines and lymphokines can be used to describe the pathogenicity of inflammatory infiltrates.

In IBD, evidence from certain of the knockout mice suggests that cytokine imbalances lead to unregulated B lymphocyte production of cytopathic autoantibodies against mucosal antigens. In NOD mice, B lymphocytes and autoantibodies apparently play a secondary role in pathogenesis. As illustrated by the effect of CFA injection, immunostimulation - far from exacerbating the development of a destructive insulitic lesion - actually retards or prevents it (14). One of the primary beta cell autoantigens appears to be the enzyme glutamic acid decarboxylase (GAD). Toleration of adolescent NOD mice with recombinant murine GAD by either intrathymic or intravenous injection prevents IDDM and reduces insulitis (36,37); interestingly, 'split' tolerance is elicited in that humoral anti-GAD titres are increased in the protected mice.

\section{DYSREGULATED CYTOKINE COMMUNICATION, CANDIDATE AUTOANTIGENS AND THE ENVIRONMENT}

The role of environmental factors remains a major unresolved question in the epidemiology of IDDM in humans. Compelling evidence that environmental factors are important modulators of genetic susceptibility to IDDM is provided by analysis of the NOD mouse model. Incidence of diabetes in NOD females is usually $80 \%$ or higher by 30 weeks of age whereas male incidence is highly variable among colonies at different institutions (in one colony, male incidence is $100 \%$ whereas it is as low as $0 \%$ in others). The environment accounts for a major component of this variation (12). Diabetes incidence in NOD males serves as a useful indicator of the presence of environmental factors affecting the penetrance of this strain's genetic susceptibility to IDDM. Transfer of NOD males from a conventional mouseroom in Japan into germfree conditions raised the male diabetes incidence from $6 \%$ to $70 \%$ (38). Exposure of NOD mice to a variety of murine viruses (encephalomyocarditis virus, lymphocytic choriomeningitis virus and murine hepatitis virus) prevents diabetes development (39-41). These infectious agents apparently protect by providing general immunostimulation since treatment of prediabetic NOD mice with various types of exogenous immunomodulators, including CFA (42), cytokines (IL-1, tumour necrosis factor-alpha, IL-2, IL-4) and poly I:C, circumvents diabetes development (14). Diabetogenic catalysts are also present in natural ingredient diets which contain lipoidal moieties that are absent or present in low concentration in semipurified diets (43). Thus, penetrance of the diabetic phenotype is strongly modified by the environment. Both mouse and rat models of IBD also appear to be strongly sensitive to environmental stimuli. HLA-B27/B2M rat IL-2 knockout mice and IL-10 knockout mice in a high specific pathogen-free state apparently suppresses IBD totally, or in the case of the IL-10 knockout, shifts the extent of the lesions from the small bowel and colon to the right colon only (personal communication).

Certain peripheral immunoregulatory functions appear to be defective in NOD mice maintained in specific pathogen-free environments as exemplified by defective $\mathrm{T}$ suppressor cell functions measured in vitro, as well as in defects in the differentiation and maturation of APC developing from bone marrow progenitors (18). Defects in the degree of cytokine-elicited differentiation of APC from bone marrow have been associated with inefficient presentation of 'self' antigens $(27,44)$. Inefficient presentation of self antigens by NOD APC may explain not only the defective tolerogenic functions of these cells, but also a number of the other dysregulated immune functions characteristic of NOD mice. These include subnormal secretion of monokines by peripheral macrophages in response to lipopolysaccharide stimulation, subnormal secretion of IL-2 and IL-4 by splenic and thymic $\mathrm{T}$ lymphocytes, respectively, depressed NK cell activity, depressed thymocyte responses to mitogenic stimulation and $\mathrm{T}$ lymphoaccumulation. Presumably, immunomodulatory effects mediated via environmental components serve to upregulate certain of these defective APC functions, resulting in more normal thymic elimination of autoreactive T lymphocytes, more potent activation of immunoregulatory $\mathrm{T}$ lymphocytes in the periphery or both.

One might presume that the target antigens/autoantigens associated with IBD and IDDM are quite distinct. If much of the inflammatory damage in IBD reflects the consequences of poorly regulated humoral responses to bacterial antigens, IBD would be seemingly distinguished from IDDM, where loss of tolerance to low abundance beta cell products, such as GAD, would be a key element in the pathogenetic process. Bacteria (Escherichia coli) produce two GAD isoforms $(52.6 \mathrm{kDa})$ immunologically cross-reactive with the two mouse isoforms (65 and $67 \mathrm{kDa})$. The recent demonstration (personal communication) that bacterial ( $E$ coli) GAD is recognized by GAD-reactive $T$ cells from NOD mice raises the following question: do mice acquire tolerance to low abundance beta cell primary autoantigens such as GAD via exposure of the mucosal immune system to high levels of bacterial homologues or to other proteins introduced through the infant's diet? A small amount of homology has been found between a low abundance beta cell autoantigen (ICA69) and a putatively diabetogenic peptide in cow's milk comprising part of bovine serum albumin (the 'ABBOS' peptide) (45). Potentially, tolerance to the beta cell autoantigen is normally acquired by exposure to the 'molecular mimic' in milk. The observation that gnotobiotic (germ-free) environments increase the penetrance of diabetogenic genes in NOD mice clearly suggests that tolerance to a subset of beta cell selfantigens is acquired through gutassociated lymphoreticular tissue expo- 
sure to bacterially derived homologues or to food proteins processed through the digestive tract. Thus, although this report has illustrated as many differences as similarities among rodent models of IBD and IDDM, regulation of mucosal immunity will prove to be an important pathway of effecting therapy in both diseases.

ACKNOWLEDGEMENTS: The writing of this review was supported by National Institutes of Health (NIH) grants DK36175, DK27722, and grants from the Juvenile Diabetes Foundation, International. Dr John Sundberg (The Jackson Laboratory) is thanked for providing information regarding large bowel histopathology, and Dr Charles Elson (University of Alabama, Birmingham) is thanked for helpful discussions.

\section{REFERENCES}

1. Strober W, Ehrhardt R. Chronic intestinal inflammation: an unexpected outcome in cytokine or T cell receptor mutant mice. Cell 1993;75:203-5.

2. Cooper H, Murthy S, Shah R, Sedergran D. Clinicopathologic study of dextran sulfate sodium experimental murine colitis. Lab Invest 1993;69:238-49.

3. Sundberg J, Elson C, Bedigian H, Birkenmeier E. Spontaneous, heritable colitis in a new substrain of $\mathrm{C} 3 \mathrm{H} / \mathrm{HeJ}$ mice. Gastroenterology 1994;107:1726-35.

4. Yang H, Shohat T, Rotter J. The genetics of inflammatory bowel disease. In: MacDermott R, Stenson W, eds. Current Topics in Gastroenterology: Inflammatory Bowel Disease. New York: Elsevier, 1992:17-51.

5. Yang H, McElree C, Roth M-P, Shanahan F, Targan S, Rotter J. Familial empirical risks for inflammatory bowel disease: differences between Jews and non-Jews. Gut 1993;34:517-24.

6. Hammer R, Maika S, Richardson J, Tang J-P, Taurog J. Spontaneous inflammatory disease in transgenic rats expressing HLA-B27 and human $\beta 2-\mathrm{m}$ : an animal model of

HLA-B27-associated human disorders. Cell 1990;63:1099-112.

7. Rotter J, Yang H. Resolving the genetics of IBD: the challenge for the 90's. Prog Inflamm Bowel Dis 1993;14:1-7.

8. Sheehy MJ. HLA and insulin-dependent diabetes. Diabetes 1992;41:123-9.

9. Todd JA, Acha-Orbea H, Bell JI, et al. A molecular basis for MHC class
II-associated autoimmunity. Science 1988;240:1003-9.

10. Nepom GT. A unified hypothesis for the complex genetics of HLA associations with IDDM. Diabetes 1990;39:1153-7.

11. Kikutani H, Makino S. The murine autoimmune diabetes model: NOD and related strains. In: Dixon FJ, ed. Advances in Immunology. New York: Academic Press, 1992:285-322.

12. Leiter E. The nonobese diabetic mouse: a model for analyzing the interplay between heredity and environment in development of autoimmune disease. ILAR News 1993;35:4-14.

13. Serreze D, Leiter E. Insulin dependent diabetes mellitus (IDDM) in NOD mice and BB rats: Origins in hematopoietic stem cell defects and implications for therapy. In: Shafrir E, ed. Lessons from Animal Diabetes. V. London: Smith-Gordon, 1994:59-73.

14. Bowman M, Leiter E, Atkinson M. Autoimmune diabetes in NOD mice: a genetic programme interruptible by environmental manipulation. Immunol Today 1994;15:115-20.

15. Shultz LD, Sidman CL. Genetically determined murine models of immunodeficiency. Ann Rev Immunol 1987;5:367-403.

16. Lampeter E, Homberg M, Quabeck K, et al. Transfer of insulin dependent diabetes between HLA-identical siblings by bone marrow transplantation. Lancet 1993;341:1243-4.

17. Vialettes B, Maraninchi D, San Marco MP, et al. Autoimmune polyendocrine failure - type 1 (insulin-dependent) diabetes mellitus and hypothyroidism after allogenic bone marrow transplantation in a patient with lymphoblastic leukaemia. Diabetologia 1993;36:541-6.

18. Leiter EH, Serreze DV. Antigen presenting cells and the immunogenetics of autoimmune diabetes in NOD mice. Reg Immunol 1992;4:263-73.

19. Faustman D, Li X, Lin HY, et al. Linkage of faulty major histocompatibility complex class I to autoimmune diabetes. Science 1992;254:1756-61.

20. Gaskins HR, Monaco JJ, Leiter EH. Intra-MHC transporter (Ham) genes in diabetes susceptible NOD/LT mice. Science 1992;256:1826-8.

21. Wicker L, Podolin P, Fischer P, Sirotina A, Boltz R, Peterson L. Expression of intra-MHC transporter (Ham) genes and class I antigens in diabetes-susceptible NOD mice. Science 1992;256:1828-30.

22. Pearce RB, Trigler L, Svaasand EK, Peterson CM. Polymorphism in the mouse Tap-1 gene. J Immunol 1993;15110:5338-47.

23. Van Kaer L, Ashton-Rickardt P, Ploegh J, Tonegawa S. TAP1 mutant mice are deficient in antigen presentation, surface class I molecules, and $\mathrm{CD}^{-} 8^{+} \mathrm{T}$ cells. Cell 1993; 71:1205-14.

24. Christianson SW, Shultz LD, Leiter $\mathrm{EH}$. Adoptive transfer of diabetes into immunodeficient NOD-scid/scid mice: relative contributions of $\mathrm{CD}^{+}$and $\mathrm{CD}^{+} \mathrm{T}$ lymphocytes from diabetic versus prediabetic NOD.NON-Thy $1^{\mathrm{a}}$ donors. Diabetes 1993;42:44-55.

25. Wicker L, Leiter E, Todd J, et al. $\beta 2$ microglobulin-deficient NOD mice do not develop insulitis or diabetes. Diabetes 1994;43:500-4.

26. Serreze DV, Leiter EH, Christianson GJ, Greiner D, Roopenian DC. MHC class I deficient NOD-B $2 m^{\text {null }}$ mice are diabetes and insulitis resistant. Diabetes 1994;43:505-9.

27. Serreze DV, Gaskins HR, Leiter EH. Defects in the differentiation and function of antigen presenting cells in NOD/LT mice. J Immunol 1993;150:2534-43.

28. Risch N, Ghosh S, Todd J. Statistical evaluation of multiple-locus linkage data in experimental species and its relevance to human studies: application to nonobese diabetic (NOD) mouse and human insulin-dependent diabetes mellitus (IDDM). Am J Hum Genet 1993;53:702-14.

29. Wilson GL, Leiter EH. Streptozotocin interactions with pancreatic B cells and the induction of insulin dependent diabetes. In: Dyrberg T, ed. Current Topics in Microbiology and Immunobiology. Berlin: Springer Verlag, 1990:27-54.

30. Gerling I, Freidman H, Greiner D, Shultz L, Leiter E. Multiple low dose streptozotocin-induced diabetes in NOD-scid/scid mice in the absence of functional lymphocytes. Diabetes 1994;43:433-40.

31. Acha-Orbea H, Mitchell DJ, Timmerman L, et al. Limited heterogeneity of $\mathrm{T}$ cell receptors from lymphocytes mediating autoimmune encephalomyelitis allows specific immune intervention. Cell 1988;54:263-73.

32. Waters SH, O'Neill JJ, Melican DT, Appel MC. Multiple TCR V $\beta$ usage by infiltrates of young NOD mouse islets of Langerhans: a polymerase chain reaction analysis. Diabetes 1992;41:308-12.

33. Maeda T, Sumida T, Kurasawa K, et al. T-lymphocyte-receptor repertoire of infiltrating $\mathrm{T}$ lymphocytes into 
NOD mouse pancreas. Diabetes 1991;40:1580-5.

34. Singh B, Rabinovitch A. Influence of microbial agents on the development and prevention of autoimmune diabetes. Autoimmunity 1993;15:209-13.

35. Shehadeh NN, LaRosa F, Lafferty KJ. Altered cytokine activity in adjuvant inhibition of autoimmune diabetes. J Autoimmun 1993;6:291-300.

36. Kaufman D, Clare-Salzler M, Tlan J, et al. Spontaneous loss of T-cell tolerance to glutamic acid decarboxylase in murine insulin-dependent diabetes. Nature 1993;366:69-72.

37. Tisch R, Yang X-D, Singer S, Liblau R, Fugger L, McDevitt $\mathrm{H}$. Immune response to glutamic acid decarboxylase correlates with insulitis in non-obese diabetic mice. Nature 1993;366:72-5.

38. Suzuki T, Yamada T, Takao T, et al.
Diabetogenic effects of lymphocyte transfusion on the NOD or NOD nude mouse. In: Rygaard NBJ, Graem N, Sprang-Thomsen M, eds. ImmuneDeficient Animals in Biomedical Research. Basel: Karger, 1987:112-6.

39. Oldstone MBA. Prevention of type 1 diabetes in nonobese diabetic mice by virus infection. Science 1988;23:500-2.

40. Wilberz S, Partke HJ, Dagnaes-Hansen F, Herberg L. Persistent MHV (mouse hepatitis virus) infection reduces the incidence of diabetes mellitus in non-obese diabetic mice. Diabetologia 1991;34:2-5.

41. Hermite L, Vialettes B, Naquet $P$, Atlan C, Payan MJ, Vague P. Paradoxical lessening of autoimmune processes in non-obese diabetic mice after infection with the diabetogenic variant of encephalomyocarditis virus. Eur J Immunol 1990;20:1297-303.

42. Sadelain MWJ, Qin H-Y, Lauzon J,
Singh B. Prevention of type 1 diabetes in NOD mice by adjuvant immunotherapy. Diabetes 1990;39:583-9.

43. Coleman DL, Kuzava JE, Leiter EH. Effect of diet on the incidence of diabetes in non-obese diabetic (NOD) mice. Diabetes 1990;39:432-6.

44. Serreze DV, Gaedeke JW, Leiter EH. Hematopoietic stem cell defects underlying abnormal macrophage development and maturation in NOD/LT mice: defective regulation of cytokine receptors and protein kinase C. Proc Natl Acad Sci USA 1993;90:9625-9.

45. Pietropaolo M, Castano L, Babu S, et al. Molecular cloning, characterization, and chromosome localization of a novel type 1 diabetes-related neuroendocrine autoantigen. J Clin Invest 1993;92:359-71. 


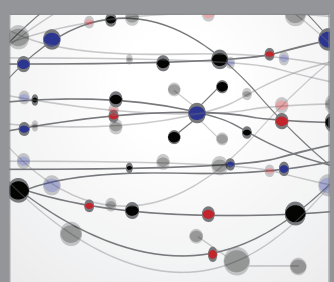

The Scientific World Journal
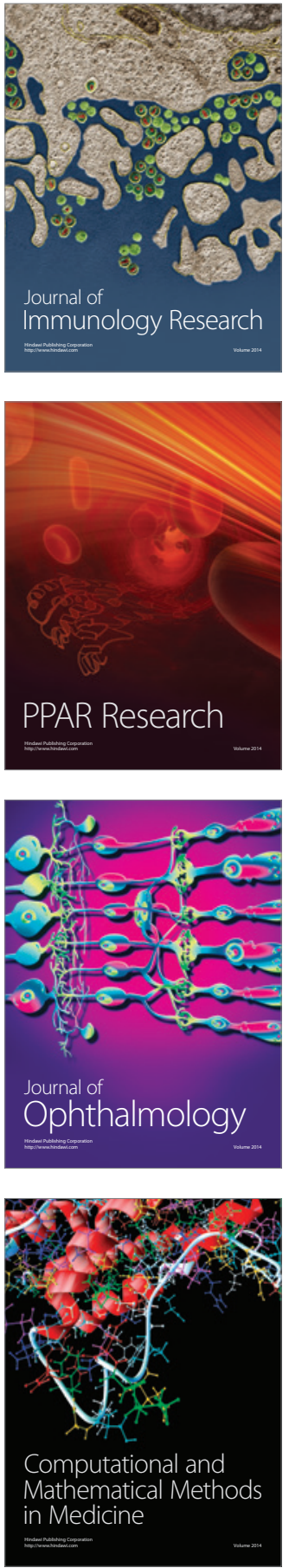

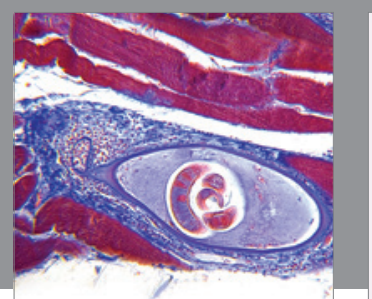

Gastroenterology Research and Practice

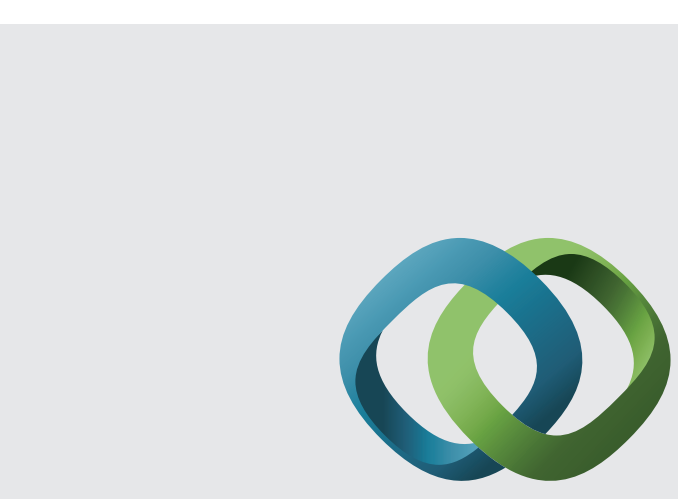

\section{Hindawi}

Submit your manuscripts at

http://www.hindawi.com
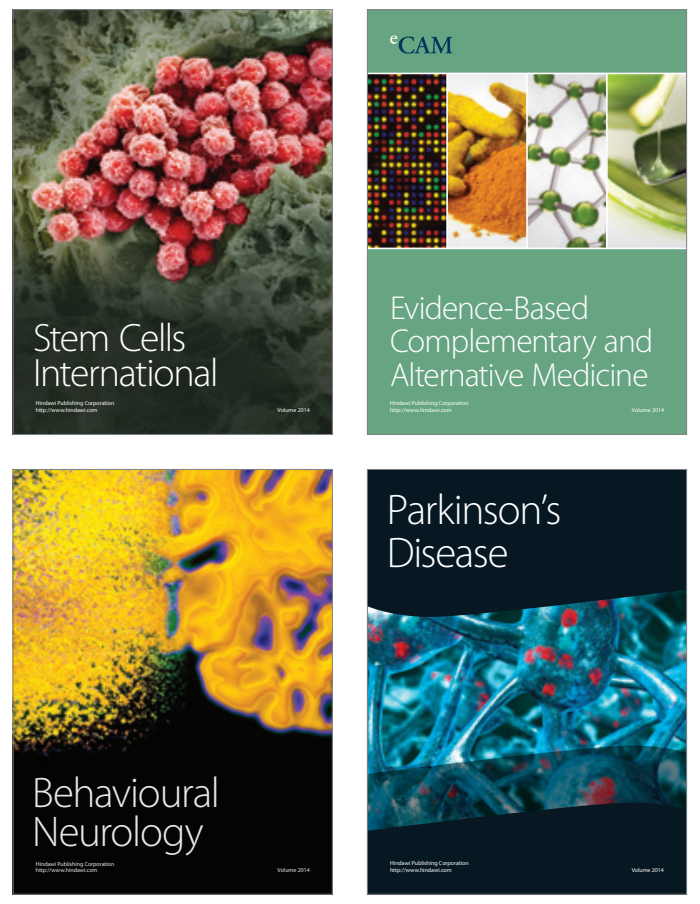
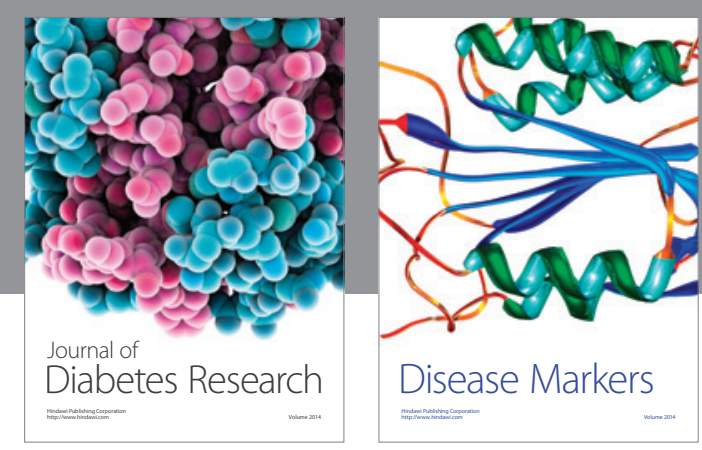

Disease Markers
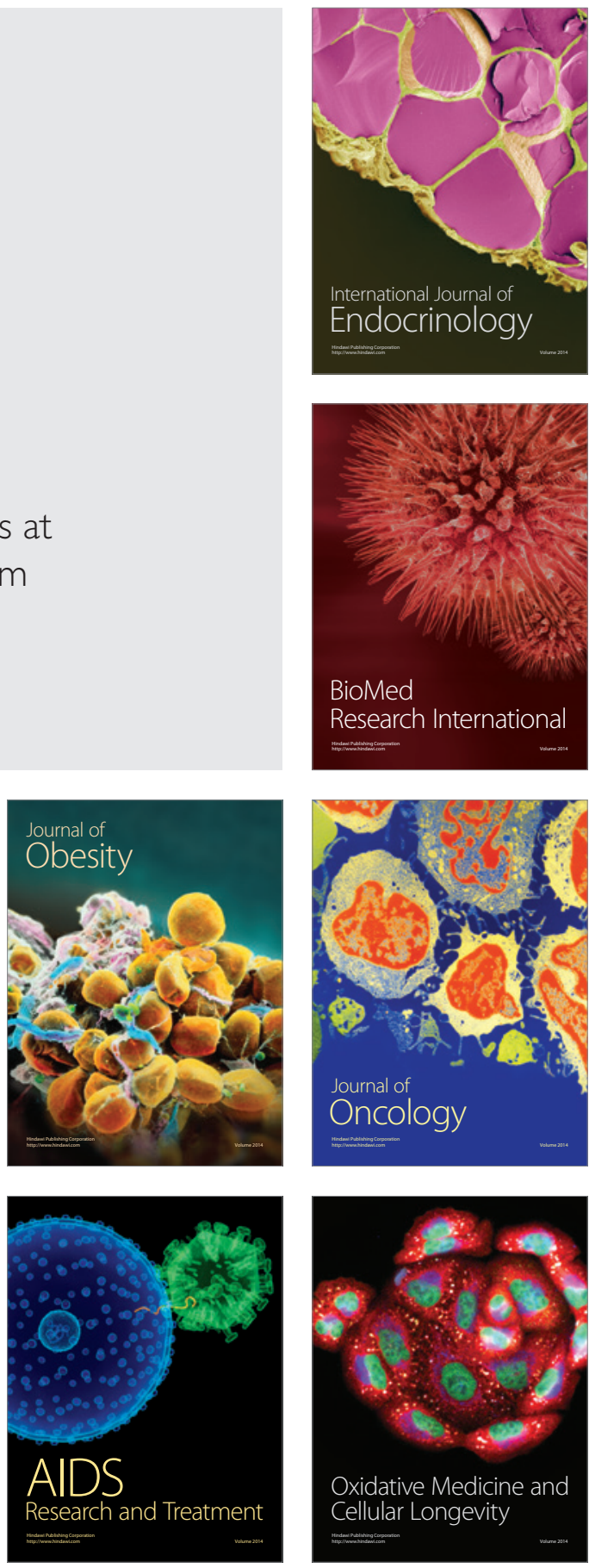